\title{
Spatial predictions of regional species distribution essential biodiversity variables (SD EBVs): A bird perspective in the Swiss
} Alps

\author{
Nasrin Amini Tehrani ${ }^{1}$, Babek Naimi ${ }^{2}$, and Michel Jaboyedoff ${ }^{1}$ \\ ${ }^{1}$ Universite de Lausanne \\ ${ }^{2}$ University of Helsinki Department of Geosciences and Geography
}

September 24, 2020

\begin{abstract}
This study aims to describe and demonstrate the applicability of a novel approach used to develop and test new methods based on species distribution models (SDMs) to establish spatial predictions of EBVs for birds based on bird diversity metrics, such as the distributions of properties of key bird habitats. A major objective of this study is to determine how to build bird SDMs that can be used to derive spatial EBVs for birds at a regional scale. We used as predictors 16 environmental variables considered ecologically meaningful for birds at $100 \mathrm{~m}$ spatial resolution, including two bioclimatic variables (Bio17 = precipitation of driest quarter and Bio7 = temperature annual range) for three periods: 'current', 'future 2050', and 'future 2070', eleven land-cover (land use) predictors (forest edge, arable land, coniferous forest, broadleaf forest, clear-cut forest, vineyard, settlement area, river, lake, meadow, and swamp forest), the normalized difference vegetation index (NDVI) and two topographic variables: slope and topography. We used multiple modelling techniques in the biomod2 package in R v3.3 to build presence-only SDMs relating bird presence to environmental features for each species. Here, we show that the suitability estimated according to the SDMs can be used as a spatial 'species distribution' EBV (SD EBV) and reflect the habitat quality and trends in climatic and land use impacts on populations of bird species. These developments should facilitate bird monitoring and management across space and time, ultimately helping to identify priority bird conservation areas, estimate habitat suitability and provide early warning signs regarding bird distribution trends. In general, bioclimatic variables, topography and forest structure were indicated to have an important relation to the species probability maps generated on the basis of the SDMs, signifying a dominant role of bioclimatic variable Bio17 in the development of habitat suitability patterns.
\end{abstract}

\begin{abstract}
Biodiversity includes many dimensions, and identifying which of them are essential is key to successful monitoring. For this reason, the concept of essential biodiversity variables (EBVs) was introduced, representing biological state variables or a group of linked variables that are measurable at particular points in time and space to document biodiversity change. In this study, among the different classes of EBVs, we selected the 'species population' class. We focused our study on subclasses of species distributions that can be described as species presence or absence based on observations that have specified spatial and temporal dimensions. This study aims to describe and demonstrate the applicability of a novel approach used to develop and test new methods based on species distribution models (SDMs) to establish spatial predictions of EBVs for birds based on bird diversity metrics, such as the distributions of properties of key bird habitats. A major objective of this study is to determine how to build bird SDMs that can be used to derive spatial EBVs for birds at a regional scale. We used as predictors 16 environmental variables considered ecologically meaningful for birds at $100 \mathrm{~m}$ spatial resolution, including two bioclimatic variables (Bio17 = precipitation of driest quarter and Bio7 = temperature annual range) for three periods: 'current', 'future 2050', and 'future 2070', eleven
\end{abstract}


land-cover (land use) predictors (forest edge, arable land, coniferous forest, broadleaf forest, clear-cut forest, vineyard, settlement area, river, lake, meadow, and swamp forest), the normalized difference vegetation index (NDVI) and two topographic variables: slope and topography. We used multiple modelling techniques in the biomod2 package in R v3.3 to build presence-only SDMs relating bird presence to environmental features for each species. Here, we show that the suitability estimated according to the SDMs can be used as a spatial 'species distribution' EBV (SD EBV) and reflect the habitat quality and trends in climatic and land use impacts on populations of bird species. These developments should facilitate bird monitoring and management across space and time, ultimately helping to identify priority bird conservation areas, estimate habitat suitability and provide early warning signs regarding bird distribution trends.

In general, bioclimatic variables, topography and forest structure were indicated to have an important relation to the species probability maps generated on the basis of the SDMs, signifying a dominant role of bioclimatic variable Bio17 in the development of habitat suitability patterns.

Keywords : Essential biodiversity variables, species distribution modelling, species distribution essential biodiversity variables (SDEBV), bird species, the Swiss Alps

\section{INTRODUCTION}

Several studies have reported a global decline or local loss of biodiversity around the world (Butchart et al., 2010; Tittensor et al., 2014; Geijzendorffer et al, 2016; Turak et al, 2017), but the available data, tools, and methods have been inadequate to reliably quantify this decline (Turak et al, 2017). In addition, obtaining good-quality information on biodiversity across whole spatial extents poses a challenge because in many regions, such information is patchy and incomplete, if not unavailable (Turak et al, 2017). Biodiversity comprises many dimensions, such as distribution, abundance, and composition, and the key to successful monitoring is thus to identify the most essential variables. For this reason, the concept of essential biodiversity variables (EBVs) (Pereira et al., 2013) was introduced to represent biological state variables or a group of linked variables that can be measurable at particular points in time and space to document biodiversity changes (Vihervaara et al, 2015; Geijzendorffer et al, 2016; Pettorelli et al, 2016; Schmeller et al, 2017; Haase et al, 2018). An EBV then offers an "interface between raw data and a calculated index" with which biodiversity alterations among different species and ecosystems can be identified and compared to regions, various taxonomic classes and various aspects of biodiversity (Brummitt et al., 2016). Conservation policy in a perfect scenario is directed towards a systematic and comprehensive awareness of the distribution of all aspects of biodiversity (Ferrier S, 2002).

This study attempts to identify key elements to be monitored, determine the rate and direction of biodiversity changes at different spatial scales and time intervals (Pereira et al., 2013; Geijzendorffer et al, 2016; Pettorelli et al, 2016; Kissling et al., 2018, Turak at al., 2017; Zilioli et al, 2019), and develop a manageable list of priority measurements for evaluating biodiversity (Brummitt et al, 2016, 2017; Latombe et al, 2017; Vihervaara et al, 2017; Turak et al, 2017). For example, in forests, variables representing genetic composition, species population attributes, community traits or habitat structure can be considered essential biodiversity variables that can be used by forest managers and policy makers to make appropriate economic and environmental management decisions (Harrington et al., 2010; De Groot et al., 2010).

An important concern in biogeographical studies that has recently been identified as one of the five 'grand challenges' in organismal biology is understanding how and why species are distributed in space and time and interact with their environment (Guisan \& Thuiller, 2005; Miller, 2010; Kissling et al., 2018). Changes in distribution and abundance of species have an impact on all aspects of biodiversity and it is crucial to track such changes to effectively protect population connectivity, its significant traits and functions, and address the potential extinction threats to species (Jarzyna, M. A., \& Jetz, W. 2017; Jetz et al., 2019). This knowledge is key to detecting "single or aggregate spatial or taxonomic units" at applicable decision-making scales (Jetz et al, 2019). The 'species distribution' EBV (SD EBV), as the second most commonly used EBV (Vihervaara et al., 2017; Kissiling et al., 2018), allows the development of indicators that reflect population trends, the extinction of threatened species, the spread of invasive species, and biodiversity responses to land 
use and climate change (Butchart et al., 2010; Kissling et al., 2018). We are able to obtain such significant information within the EBV class of species population, which is defined as a 'space-time-species-gram (cube)' and is identified according to the three subclasses of species distribution, population abundance, and population structure (Pereira et al., 2013; Kissling et al., 2018; Jetz et al., 2019).

The SD EBV, defined as the presence or absence of species, is therefore represented by a binary variable of presence (1) or absence (0) in many cases (Pereira et al., 2013; Latombe et al., 2017; Kissling et al., 2018; Jetz et al, 2019). Species distributions can be estimated by predictive modelling, such as through the use of species distribution models (SDMs) (Guisan et al, 2006; Elith \& Leathwick, 2009; Pettorelli et al, 2016; Turak et al, 2017; Kissling et al., 2018), since such models statistically relate to the distributions of populations (Guisan et al, 2017). The use of SDMs can support biodiversity monitoring initiatives to be directed to areas where it is more likely to locate species under the focus of the conservation program (Tulloch \& Szabo, 2012; Turak et al. 2017). These models are useful numerical tools employed to integrate the observed abundance or occurrence of species and environmental predictors to predict species distributions, environmental suitability, or the probability of species occurrence across a landscape and provide great opportunities to learn about the past, current, and future distributions of species (Elith \& Leathwick, 2009; Guillera-Arroita et al., 2015; GEO BON, 2015; Naimi \& Araújo, 2016; Vihervaara et al, 2017; Jetz et al, 2019; Dantas de Paula et al., 2019). Therefore, SDMs can characterize ecological niches using environmental predictors to predict the presence/absence of a species in the study area (Hirzel et al, 2008; Vihervaara et al, 2017; Jetz et al, 2019), and the spatial patterns of species distributions can provide information regarding the rarity and potential extinction risk of species, which is essential to effective monitoring (Kissling et al, 2018; Jetz et al, 2019).

Some studies have attempted to shift the current focus from global and international monitoring to national and even local geographical application of EBVs, arguing that biodiversity is better understood at national or regional level in terms of 'local eco-evolutionary processes' (Vihervaara et al., 2017). EBVs can also become more practical and informative at a national monitoring level, as high-quality biodiversity data are an essential component of environmental models that attempt to describe the ecosystem (Michener \& Jones, 2012; Vihervaara et al., 2017). Obtaining representative datasets of EBVs will depend on how the data are integrated, by means of data harmonization (EBV-ready datasets) and modelling effort (derived and modeled EBV data), with other EBVs. Such integration relies on the indicators that could be used to determine which classes of EBVs could be quantified with existing datasets and the development of proper monitoring frameworks to resolve major data gaps (Henry et al., 2008; Legnyel et al., 2008; Geijzendorffe et al., 2016; Proença et al., 2017; Vihervaara et al., 2017; Kissling et al., 2018). Bird and butterfly data, for instance, can be used as quantifying indicators to determine "the added value of dataset integration" for the assessment of species abundance at large scales (De Heer et al., 2005; Gregory et al., 2005, 2009; Geijzendorffe et al., 2016).

The development of models and indicators of EBV candidates, such as species distributions, and their responses to drivers of biodiversity change and 'regime shifts' has been identified as the main challenge in several studies (Pereira et al., 2013; Turak et al, 2017). In these studies, indicators are considered to be efficient and capable of accessing and synthesizing the wealth of data for a given EBV candidate, such as species distributions, and appear to be sufficiently powerful to convey information on the status of biodiversity. The Red List Index, for example, is partly composed of data on two different EBV variables, abundance of species and their distributions, that can reflect changes in species abundance and distribution and be used to monitor species conservation status across space and time (Pereira et al., 2013; Pettorelli et al, 2016; Turak et al, 2017).

In a review, Kissling et al., 2018 addressed challenges related to 'Big Data' in biodiversity and how to build global EBV data products from multisource datasets. They found that building reliable and representative global EBV data products from multiple sources entails filling data gaps at the spatial, temporal and taxonomic scales and benefits from the use of accessible or no restricted data. Geijzendorffer et al., 2016 used EBVs to identify gaps in the reporting requirements for biodiversity and the available information. They evaluated how the mobilization, modelling and continuous processing of the current data could lead to a reduction in 
such gaps. The ongoing development of the EBV framework has been observed to limit spatial, temporal and realm analyses and essential information on changes in biodiversity. As an enhanced strategy for site-based long-term future studies, Haase et al., 2018 proposed incorporating two frameworks of ecosystem integrity (EI) and EBVs. Their recommendations of variables, measurements, and instrumentation could lead to the global harmonization of field research, and any researcher who does some type of ecological field work could use these guidelines as a framework for the systematic collection of environmental data.

Among the different EBV classes, in this study, we focus primarily on the species-level distribution of biodiversity as an EBV candidate for the EBV population class to aid the implementation of the EBV framework at the species level (Pereira et al., 2013; Kissling et al., 2015; Geijzendorffer et al., 2016). This study aims to evaluate and demonstrate the applicability of SDMs to establish spatial predictions of the EBV candidate 'species distribution' in the EBV population class for bird species (as a regional indicator, as EBVs are scalable and tend to change in size and scale) based on bird diversity metrics, such as the distribution and abundance of properties of key bird habitats. One of the main objectives of this study is to determine how to develop more accurate bird indicators for three periods (current, future 2050, future 2070) in response to land use and climate change (Butchart et al., 2010; Kissling et al., 2018) based on SDMs that can be used to derive spatial species distributions for birds under climate change and variation in land use, as bird SDMs can be used as a small part and a spectrum from national to regional scales in the development of a spatial EBV for birds (Huntley et al., 2004, Elith \& Leathwick, 2009; Vihervaara et al., 2017).

As outputs of models, these indicators can convey information regarding the status of bird species so that changes in the conservation status of species can be monitored across a temporal framework and provide a great opportunity to learn more about the past, current, and future distributions of species (MacKenzie et al., 2006; Elith \& Leathwick, 2009; Guillera-Arroita et al., 2015; Naimi \& Araújo, 2016; Turak et al., 2017; Jetz et al., 2019; Dantas de Paula et al., 2019). These developments should therefore facilitate the monitoring and management of bird distributions across space and time, as conservation planning requires the identification of habitats (Gogol-Prokurat, M., 2011), which will ultimately help to identify priority bird conservation areas and estimate habitat suitability and can provide early warning signs regarding bird distribution trends (Elith et al., 2006; Brummitt et al., 2017). Such information also helps to identify the obstacles affecting regional species distributions, as partial consideration of the SD EBV, in current and future times (Butchart et al., 2010; Pereira et al., 2013; Tittensor et al., 2014).

In this study, we used occurrence data for 14 bird species as raw data in the first step of the 'derived and modeled EBV data' workflow (Kissiling et al., 2018), considered the SD EBV on a regional scale and built spatial SDMs as EBVs occurring between the raw bird data and indicators (indices derived from the SD EBV) to map current and future species distributions to identify areas of optimal habitat suitability (Hirzel et al., 2006; Brummitt et al., 2017). These developments could support the protection and management of bird species across space and time, ultimately help define bird protection and habitat adequacy targets and provide early warning signs related to bird distribution patterns.

\section{MATERIALS AND METHODS}

2.1 Study area and species data

\section{Hosted file}

image1.emf available at https://authorea.com/users/361270/articles/482723-spatialpredictions-of-regional-species-distribution-essential-biodiversity-variables-sd-ebvs-abird-perspective-in-the-swiss-alps

The study area is located in the western Swiss Alps in Vaud (46deg10' to 46deg30'N; 6deg50' to 7deg10'E; Figure 1). Since 2013, it has been an interdisciplinary and transdisciplinary research site for the University of Lausanne, and it currently belongs to the Interdisciplinary Center for Mountain Studies (CIRM) (http://rechalp.unil.ch). It covers an area of approximately $700 \mathrm{~km}^{2}$ and an elevational gradient extending from Lake Geneva at $372 \mathrm{~m}$ a.s.l. to Pointe des Diablerets at 3,210 m a.s.l. (Descombes et al., 2017; 
Scherrer et al., 2019). This area is negatively affected by human activity, such as the dense population and intensive farming in the Rhone Valley, tourism and leisure activities, and more extensive farming in the subalpine regions characterized by a mosaic of meadows, pastures, and forest and woodland patches (see http://rechalp.unil.ch; Randin et al., 2009; Scherrer et al., 2019; Amini Tehrani et al., 2019). The bird data were obtained from the Swiss Ornithological Institute (Monitoring Haufige Brutvogel [MHB]; Schmid et al., 2004), with data collection beginning in 1999 and performed annually (for more information on the survey, seehttps://www.vogelwarte.ch/de/projekte/monitoring/monitoring-haeufige-brutvoegel), Swiss Breeding Bird Atlas 2013-2016 (Knaus et al., 2018; see https://www.vogelwarte.ch/en/projects/monitoring/swissbreeding-bird-atlas), and Swiss Biodiversity Monitoring [BDM], an ongoing biodiversity monitoring program including bird species richness data collected since 2001 that are updated annually, to obtain information on the populations of the most common species in terms of trends and changes in range size. Surveys and monitoring methods follow those of the Sempach's Common Breeding Bird Survey (MHB) of the Swiss Ornithological Institute (BDM 2014), which are described in detail in the following paragraphs (more details athttp://www.biodiversitymonitoring.ch/en/background.html). These data were collected on the basis of the systematic sampling (1263 sampling points) of 267 quadrats, each covering $1 \mathrm{~km}^{2}$, located as grid cells distributed across Switzerland (39 quadrats are located in our study area). The data were collected three times during the breeding season (15 April-15 July) and twice for quadrats located above the timberline at an elevation of approximately $2000 \mathrm{~m}$. Each survey took 3-4 hours along a 4-6 km transect, along which breeding birds were marked according to visual observations or acoustic identification (Royle et al., 2007; Kery \& Royle, 2009). A set of 14 bird species were used in this study, with 11 species known as near threatened (NT) and 3 vulnerable (VU) based on the national red list (Table S1). This classification allowed us to apply the research approach to a wide range of rare to poorly sampled bird species. We only considered birds with a sample size of greater than 20 presence records, as species with fewer presence records are not deemed appropriate for use in modelling due to errors connected with very small sample size (Thuiller et al., 2005).

\subsection{Environmental data}

We used as predictors 16 environmental variables that are considered ecologically significant and affect mobile species such as birds (Jaberg \& Guisan, 2001), with data collected from multiple sources at $100 \mathrm{~m}$ spatial resolution (Table 1) (more information in supplementary information) and manipulated the data in ARCGIS 10.2 (Environmental System Research Institute, Inc.) or R 3.3 (R Core team, 2016). These variables include two bioclimatic variables, Bio17 (precipitation of driest quarter) and Bio7 (temperature annual range), with data for the three periods of current, future 2050, and future 2070 derived from MeteoSwiss GridData Products at $1 \mathrm{~km}$ resolution, eleven land-cover (land use) predictors (including forest edge, arable land, coniferous forest, broadleaf forest, clear-cut forest, vineyard, settlement area, river, lake, meadow, and swamp forest (with the proportion of each land-cover type across the area calculated with a land-cover layer (Geostat 2013/2018, OFS) reclassified into two classes (1 or 0)), the normalized difference vegetation index (NDVI; Rouse et al. 1973), and two topographic variables: slope and topography. The variables were chosen as to not be too highly correlated (Spearman correlation $<0.7$ ) (Dormann et al., 2013). For details regarding the environmental variables, see Table 1 and the supplementary methods.

\subsection{MODELLING}

\subsubsection{Species distribution models}

The SDMs were constructed with modelling algorithms to explain the correlation between the bird occurrence data and geographically coincident environmental variables (Manel et al, 1999; Distler et al, 2015). We used multiple modelling techniques (Guisan et al., 2017) in the biomod2 package (Thuiller et al., 2016) to build presence-only SDMs for each species in R v3.3 (R Core Team, 2016) relating bird presence to the environmental variables (Brambilla \& Ficetola, 2012). Our choice of modelling techniques was aimed at capturing the variability in the different classes of algorithms (e.g., regression-based and regression-tree) and taking advantage of the use of different algorithms on the same platform (Meller et al., 2014). We

combined the outputs from the different algorithms to obtain the best results (Guisan et al, 2017). SDMs 
include generalized linear models (GLMs), as an example of a parametric regression-based approach with a strong statistical foundation that is particularly useful for habitat suitability modelling (Guisan et al., 2002; Austin, 2002, Guisan et al., 2017), multivariate adaptive regression splines (MARS; representing a regression technique providing an alternative regression-based method for fitting nonlinear responses using piecewise linear fits rather than smooth functions) (Elith et al, 2006; Leathwick et al, 2006), generalized boosting models (GBM; boosted regression trees, multivariate nonparametric regression and data-adaptive techniques) (McCaffrey et al, 2004) and random forest (RF; an ensemble learning technique based on combining a large set of decision trees) (Dobrowski et al, 2011; Vincenzi et al, 2011). All models were calibrated with presenceonly data and 10,000 pseudo-absence records randomly selected (Wisz \& Guisan 2009; Breiner et al., 2015; Thuiller et al., 2016) with the disk parameter to prevent pseudo-absences selection within a radius of $1 \mathrm{~km}$ from a training presence (Progin et al., 2018). As unbalanced prevalence reduces the accuracy of the models, the pseudo-absences were weighted equally to the presence (prevalence of 0.5; Ferrier et al., 2002; Thuiller et al., 2016; Guisan et al.,2017; Thuiller \& Zimmermann, 2017; Scherrer et al., 2019). Model accuracy was evaluated with a repeated (10 times) split-sample procedure. An evaluation dataset was obtained by randomly drawing $30 \%$ of the records from the original dataset. The remaining $70 \%$ were used as training data to fit the models.

\subsection{Projecting distributions}

We used an ensemble of models (e.g., fitted with different modelling methods or with different sets of predictors) (Palialexis et al, 2011), as the general predictions obtained from two or more models, even when they contain different environmental predictors, may show equal predictive performance. This results in different spatial predictions and makes it impossible to know which of the equivalent candidate models should be used (Randin et al, 2006; Guisan et al, 2017). To describe the current and future distributions of bird species, we projected the SDMs for all 14 species into a mean climate space for three time periods: the current time (1981-2010), future 2050 (2045-2074), and future 2070 (2070-2099). The models estimated the birds' distributions for the current time and projected them into the future given the bioclimatic predictors Bio7 and Bio17. This process resulted in three grid outputs (current, future 2050, and future 2070) for each species. To obtain the predicted species distribution maps for the current time, we stacked climatic suitability values across all SDMs and then averaged the suitability values (Distler et al, 2015). To generate probability maps (mean habitat suitability) for each time in the future (2050 and 2070), we considered the impact of climate change under the future emission scenario A2, which is commonly considered to be the worst-case scenario, describing a heterogeneous world with a continuously increasing global population (Sheffield \& Wood, 2008; Mokany et al., 2012). We then stacked the individual projected probabilities of all species predictions to yield the projected species distribution (Mateo et al, 2012).

\subsubsection{Changes in species relative abundance}

Predicted species abundance is related only indirectly to how much habitat is maximally occupied by species (Zurell et al, 2012). The trends of the changes in species abundance and distribution can be used to monitor changes in the conservation status of species across time (Turak et al, 2017). Predictions of the changes in species relative abundance were made for the current time, future 2050 and future 2070 . Then, we used the criteria used for the identification of IUCN Red List categories (critical, endangered and vulnerable) for conservation purposes (Bibby et al, 2000).

\subsection{Model performance}

We used three statistics to evaluate the predictive performance of the models: the area under the receiver operating characteristic curve (AUC), which has been commonly used for measuring the performance of SDMs, the true skills statistic (TSS), and Cohen's kappa statistic (KAPPA) (Cohen 1960; Allouche \& Kadmon, 2006; Fernandes et al., 2018). These techniques were used to assess the agreement between the presence and pseudo-absence records and the predicted probability of occurrence (Elith et al, 2006) and analyze the uncertainty around the mean from different algorithms (ensemble models) (Barry and Elith, 2006; Van Niel \& Austin, 2007; Guisan et al., 2017). Here, we applied weighted model averaging across the 
four modelling methods (Wintle et al., 2003; Guisan et al, 2017).

\section{RESULTS}

\subsection{Important predictors and model performance}

When averaging the individual bird species distributions across all species, precipitation of driest quarter (Bio17), coniferous forest (coniferous), and topography (topo) were the variables showing the greatest relative contributions to the model fits $(0.16,0.14$, and 0.13, respectively) (Figure 2). For the near-threatened (NT) species, Bio17 (0.17), topo (0.10) and forest edge (0.10) showed a positive relationship with the species probability maps, while for vulnerable (VU) species, coniferous (0.20), topo (0.15), Bio17 (0.14) and temperature annual range (Bio7) were the most important predictors. In the SDMs, bioclimatic variables generally had a significant relationship with the species probability maps, suggesting that Bio17 plays a dominant role in shaping patterns of habitat suitability (Distler et al, 2015). The SDMs with ROC, KAPPA, and TSS scores of $0.71,0.38$, and 0.67 , respectively, and a mean AUC score $=0.71$ had good performance in predicting the distributions of bird species (Araujo et al., 2005) (Figure 3, 4).

\subsection{Current and future patterns of species distributions}

The SDMs provided relatively the same estimated patterns of current and future distributions across the two groups of species (near threatened (NT) and vulnerable (VU)) (Figure 5). The estimated habitat suitability at the current time peaked in the eastern part of the study area, along the highland area, agricultural area and forest edge; conversely, lower latitudes and areas with lower elevations supported fewer species. In the future (2050), the species distributions are expected to increase across sections of the central, northern and southeastern parts of the study area according to the SDMs, and suitable habitat is projected to extend into these parts of the study area at high altitudes. In 2070, higher altitudes and areas with higher elevations are expected to support more species across most of the eastern and southern parts of the study area and into northern parts. These results suggest that in the future, higher altitudes in the study area will support more species, especially in the eastern part.

3.3 Changes in current and future species relative abundance

The results highlight that the relative abundance of all 14 evaluated species except for Tetrao tetrix (Black Grouse) andEmberiza cirlus (Cirl Bunting) will gradually increase from the current time to the future (2050 and 2070) (Figure 6). T. tetrixshowed a decline in relative abundance of $9.10 \%$ between 2050 and 2070 (20 years), and for Emberiza cirlus, there was a small decrease $(0.17 \%)$ between the current and future times (2050), with a decrease of $1.41 \%$ between 2050 and 2070 (Figure 6). These species could thus be in danger in 2070, especially T. tetrix, which could become vulnerable (VU) by 2070, as this species was predicted to lose $10 \%$ of its abundance over 20 years (Pereira et al., 2013; IUCN. (2010); Pettorelli et al, 2016). The abundances of Alectoris graeca, Delichon urbicum, and Sylvia borin were predicted to increase negligibly from the current time to the future (2050) and to experience a slight declining trend between 2050 and 2070. Thus, for these three species, a nonsignificant change from the beginning of the current time to 2070 is expected to occur, and the trend of species abundance during the three evaluated times will change approximately insignificantly.

\section{DISCUSSION}

A major focus of this work was to consider EBVs at a regional scale (western Swiss Alps) by building spatial SDMs, map current and future species distributions to identify areas of optimal habitat suitability (Hirzel et al, 2006; Brummitt et al, 2017), and ultimately identify priority conservation areas for bird species at this scale (Elith et al, 2006; Gogol-Prokurat, M. 2011). Here, we examined the SD EBV at the regional 
scale to evaluate the response of bird species to land use and climate change (Huntley et al. 2004, Elithand \& Leathwick, 2009) and then provided useful information for conservation planning (Brotons et al, 2004; Brummitt et al, 2017; Latombe et al, 2017) that could be scaled up to the national level. As a partial consideration of the SD EBV, it was also important to explore which barriers currently and in the future negatively affect regional species distributions (Butchart et al., 2010; Pereira et al., 2013; Tittensor et al., 2014). One of the most efficient approaches is to help practitioners with interpretation in planning and the application of management decisions; therefore, the models and distribution maps involving the SD EBV on a regional scale can be used as comprehensive and practical tools for biodiversity conservation decisions (Turak et al, 2017) and applied at a larger scale both nationally and globally.

4.1 Variable importance and species distribution maps

Our results are consistent with the finding that the most important variables are the bioclimatic variable of precipitation of driest quarter (Bio17), subalpine forest (coniferous forest) and topography. These variables are positively related to the occurrence probability of the species (Stephan et al. 1992; Hatchwell et al. 1996), and most of the species considered in this study inhabit alpine, subalpine, flower meadow, and montane forest edge habitat and brood on the ground in mown meadows in highland areas (Muller et al., 2005; BergerFluckiger et al., 2008; Liedvogel et al., 2018; Horch \& Spaar, 2010, 2016). Therefore, conservation efforts should focus on managing agricultural areas and forest edges to optimize the habitat for these species. In addition, we identified strong bioclimatic dependencies that account for preference of species for altitudinal scale and the related forest ecosystems (von dem Bussche et al., 2008). These results are consistent with predictions from climate-based hypotheses, which suggest that upward shifts in bird distributions in the future are expected to result from climate warming and that these species track climate change (Maggini et al, 2011; Chen et al, 2011; Zbinden \& Haller, 2013; Roth et al, 2014). In May and June (breeding season), temperatures are high and little rainfall occurs, causing many alpine birds to temporarily move to higher altitudes (Sattler et al, 2017). Therefore, species will benefit from warmer temperatures and eventually extend their habitat scale to higher elevations (Hughes, L. 2000; Parmesan \& Yohe, 2003; von dem Bussche et al., 2008).

The results of our study also indicate that lower temperatures are critical for the distribution of most species in this mountainous area, as they respond negatively to higher temperatures, moving to higher altitudes in response (see Maggini et al., 2011; Maggini et al., 2014). Therefore, the findings reveal that bird populations would possibly be impacted by climate change during the breeding season due to the seasonal rise in temperature.

The findings of our study show that in the western Swiss Alps, climate, specifically temperature, is the key driver of bird distributions, such that slight variations in temperature can cause bird species to ascend in elevation during the breeding season. As previously reported, the most extreme impacts of climate change on high mountains such as the Alps are anticipated to occur by the end of the 21st century (Beniston et al. 1997; Hughes, L. 2000; Sergio, \& Newton, 2003), and in the western Alps, sudden habitat loss is expected to occur under certain climate change scenarios.

We conclude that vulnerable species, such as Ring Ouzels, show structure-dependent occurrence rather than direct exclusion through other effects (Buchanan et al. 2003). Altered landscape patterns such as transition of deciduous forest to higher elevations and the expansion of forests to farmlands would possibly have a profound effect on the distribution of Blackbirds and Ring Ouzels because of extreme changes in land cover. Indeed, reforestation and new plantings have negative effects on Ring Ouzels (Bolliger et al., 2000; Sigmaplan et al., 2001; Horch \& Holzgang, 2006; von dem Bussche et al., 2008). For these species, the combination of mowing practices in accordance with the species' breeding phenology (Muller et al., 2005) and low input of fertilizer in grassland (e.g., the further restriction of liquid manure application, a very common practice in Switzerland that is acceptable in organic production) would certainly be key conservation measures (Richner \& Tippet, 1999; Muller et al, 2005; Britschgi et al., 2006, Horch \& Spaar, 2016).

The Black Grouse (T. tetrix ) is another example of a species that sensitively reacts to the abandonment of 
alpine summer pastures and the subsequent intrusion of shrubs and trees (Patthey et al, 2012; Zurell et al, 2012). The Black Grouse occupies the same narrow altitudinal belt around the timberline where snow-sports activities generally occur (Menoni \& Magnani, 1998; Zeitler \& Glanzer, 1998; Zeitler, 2000), highlighting the necessity of establishing wintering refuges as a result of anthropogenic factors linked to outdoor snowsports activity rather than other factors such as hunting pressure or breeding habitat quality (Patthey et al. 2008). Snow sports cause disturbance and stress to wildlife (Korner; 2000). Therefore, structural elements are crucial in explaining species incidences, and thus temperature and altitudinal conditions are less important for these species (Bolliger, 2002). Breeding Black Grouse hens require a patchy mosaic of diverse types of vegetation, none of which overwhelms the landscape, not just at the local foraging scale but also within the broader habitat matrix (Braunisch et al, 2016; Patthey et al, 2012;). The simplest and most efficient solution thus far is to create winter refuges that limit to a minimum the interaction between snow-sports participants and Black Grouse, as demonstrated by the success story reported in Arlettaz et al. $(2013,2015)$. The creation of wildlife refuges, by limiting human access to key habitats of vulnerable or endangered species, has proven to be an effective tool in this context (Knight \& Temple, 1995, Whitfield et al.2008).

\subsection{Species abundance}

By 2070, the population size and occupied area for most of the species were predicted to be primarily controlled by currently positive population growth and gradually increased from the beginning of the current time to the future (2050 and 2070) across all climate scenarios (A2) and SDM algorithms. Thus, it could be interpreted that the increasing number of territories over the course of the season might not only be due to the late arrival of birds from the wintering grounds but also to the abandonment of primary territories after nest loss at unmonitored sites nearby (Gruebler et al. 2015). Predictions of species abundance from the current time to the future show that all species except T. tetrix (Black Grouse) have no risk of extinction.

\section{Conclusion}

This work will ultimately allow us to consider the SD EBV at the regional scale in accordance with modelbased evaluation (SDM) to predict and monitor ongoing and future changes in bird species distributions as a part of the Switzerland indicator assessment that is occurring in the study area (Guisan et al, 2017) and to measure and present bird responses to environmental changes for three periods of time (Brummitt et al, 2017; Schmeller et al, 2017; Kissling et al., 2018; Proenca et al, 2017; Jetz et al, 2019; Hardisty et al, 2019, Zilioli et al, 2019). We now understand how and why species are distributed across space and time and the relationships between species and their environment in such a heterogeneous study area. Therefore, the patterns of the spatial distribution of species as a partial SD EBV or the path toward national implementation can inform us about rarity and potential extinction risk for species and are essential for effective monitoring (Jetz et al, 2019). This study demonstrates the importance of low temperatures at high elevations and forest structures for bird species in a mountainous area. The distribution of bird species in this mountain area seems to be determined by abiotic interactions rather than biotic interactions (Guisan et al, 2017).

Despite years of national coordination to address the loss of bird diversity, losses of species and their habitats continue to occur. Therefore, to successfully prevent future species distribution loss, urgent progress on methods for tracking and reporting bird distribution changes is needed. As national and global information on bird species distributions could be essential, reporting and managing bird species and providing an overview of bird distribution trends in different time periods can indicate whether suitability obtained through SDMs on a regional scale can be used as a small part or a spectrum of national to subnational indicators of a spatial 'species distribution' EBV (SD EBV) for bird species (Brummitt et al, 2017; Latombe et al, 2017; Jetz et al, 2019). Several challenges remain to be solved when building species distribution EBVs. For example, models and standards have been developed to predict the distributions of birds across species and scales through the remote sensing of habitat cover (satellite remote sensing), as such information plays a crucial role in building species distribution EBVs and is ideal for evaluating biodiversity changes (Schimel et al, 2013; Vihervaara et al, 2017; Kissling et al., 2018; Proenca et al, 2017; Dantas de Paula et al, 2019). EBV frameworks are applicable to a broad range of spatial, temporal and taxonomic scales (Zilioli et al, 2019), and we hope that 
our study contributes to fostering further research on EBVs.

Acknowldgements

We would like to thank Dr. Thomas Sattler from the Swiss Ornithological Institute for providing species data and collaboration. NAT is a doctoral student at the University of Lausanne and was supported by a scholarship from Iran's Ministry of Science, Research and Technology and financial help from the University of Lausanne.

Conflict of interest

None declared.

Author Contributions

NAT designed the study, applied the methodology, and analyzed data with input from all authors. NAT led the writing of the manuscript. All authors contributed critically to the drafts and revised, read, and approved the final manuscript.

Data Availability Statement

The data that support the findings of this study are available from the Swiss Ornithological Institute but restrictions apply to the availability of these data, which were used under license for the current study, and so are not publicly available.

References

Allouche, O., Tsoar, A. and Kadmon, R. (2006) Assessing the accuracy of species distribution models: prevalence, kappa and the true skill statistic (TSS). Journal of Applied Ecology, 43: 1223-1232. doi:10.1111/j.13652664.2006.01214.x.

Amini Tehrani, N., Naimi, B., \& Jaboyedoff, M. (2020). Toward community predictions: Multi-scale modelling of mountain breeding birds' habitat suitability, landscape preferences, and environmental drivers. Ecology and Evolution .

Araujo, M. B., Pearson, R. G., Thuiller, W., \& Erhard, M. (2005). Validation of species-climate impact models under climate change. Global Change Biology, 11(9), 1504-1513.

Arlettaz, R., Patthey, P., \& Braunisch, V. (2013). Impacts of outdoor winter recreation on alpine wildlife and mitigation approaches: a case study of the Black Grouse. The Impacts of Skiing and Related Winter Recreational Activities on Mountain Environments (eds C. Rixen \& A. Rolando), S, 137-154.

Arlettaz, R., Nussle, S., Baltic, M., Vogel, P., Palme, R., Jenni-Eiermann, S., .. \& Genoud, M. (2015). Disturbance of Wildlife by Outdoor Recreation. Bulletin of the Ecological Society of America, 96(3), 475-477.

Austin, M. P. 2002. Spatial prediction of species distribution: an interface between ecological theory and statistical modelling. / Ecol. Modell. 157: 101/118.

Barry, S., \& Elith, J. (2006). Error and uncertainty in habitat models. Journal of Applied Ecology, 43(3), 413-423.

Beniston, M., Diaz, H. F., \& Bradley, R. S. (1997). Climatic change at high elevation sites: an overview. Climatic Change, 36(3-4), 233-251.

BERGER-FLUCKIGER, A., H. HORCH \& O. BIBER (2008): Regression et disparition d'une population de Tariers des pres Saxicola rubetra sur le Plateau de Diesse (Jura bernois, Suisse) entre 1972 et 2007. Nos Oiseaux 55: 99-108.

BON, G. (2015). Global Biodiversity Change Indicators. Version 1.2. Group on Earth Observations Biodiversity Observation Network Secretariat. Leipzig. 
Bolliger, J. (2002). Schweizer Walder und Klimaveranderungen: Vergleich von Simulationen quantitativer Vegetationsmodelle| Swiss forests and climate change: comparison of simulated quantitative vegetation models. Schweizerische Zeitschrift fur Forstwesen, 153(5), 167-175.

Bibby, C., Jones, M., \& Marsden, S. (2000). Bird surveys. Birdlife International, Cambridge, UK, 137.

Brummitt, N., Aletrari, E., Syfert, M. M., \& Mulligan, M. (2016). Where are threatened ferns found? Global conservation priorities for pteridophytes. Journal of systematics and evolution, 54(6), 604-616.

Brambilla, M., \& Ficetola, G. F. (2012). Species distribution models as a tool to estimate reproductive parameters: a case study with a passerine bird species. Journal of Animal Ecology, 81(4), 781-787.

Braunisch, V., Patthey, P., \& Arlettaz, R. (2016). Where to combat shrub encroachment in alpine timberline ecosystems: combining remotely-sensed vegetation information with species habitat modelling. PloS one, 11(10).

Breiner, F. T., Guisan, A., Bergamini, A., Nobis, M. P. and Anderson, B. (2015), Overcoming limitations of modelling rare species by using ensembles of small models. Methods Ecol Evol, 6: 1210-1218. doi:10.1111/2041-210X.12403.

Britschgi, A., Spaar, R., \& Arlettaz, R. (2006). Impact of grassland farming intensification on the breeding ecology of an indicator insectivorous passerine, the Whinchat Saxicola rubetra: Lessons for overall Alpine meadowland management. Biological Conservation, 130(2), 193-205.

Brummitt, N., Regan, E. C., Weatherdon, L. V., Martin, C. S., Geijzendorffer, I. R., Rocchini, D., ... \& Schmeller, D. S. (2017). Taking stock of nature: Essential biodiversity variables explained. Biological Conservation, 213, 252-255.

Brotons, L., Thuiller, W., Araujo, M. B., \& Hirzel, A. H. (2004). Presence-absence versus presence-only modelling methods for predicting bird habitat suitability. Ecography, 27(4), 437-448.

Buchanan, G. M., Pearce-Higgins, J. W., Wotton, S. R., Grant, M. C., \& Whitfield, D. P. (2003). Correlates of the change in Ring Ouzel Turdus torquatus abundance in Scotland from 1988-91 to 1999. Bird Study, 50(2), 97-105.

Butchart, S. H., Walpole, M., Collen, B., Van Strien, A., Scharlemann, J. P., Almond, R. E., . . \& Carpenter, K. E. (2010). Global biodiversity: indicators of recent declines. Science, 328(5982), 1164-1168.

Chen, I. C., Hill, J. K., Ohlemuller, R., Roy, D. B., \& Thomas, C. D. (2011). Rapid range shifts of species associated with high levels of climate warming. Science, 333(6045), 1024-1026.

Cohen, J. (1960). A coefficient of agreement for nominal scales. Educational and Psychological Measurement, 20, 37-46. https://doi. org/10.1177/001316446002000104.

Dantas de Paula, M., Gomez Gimenez, M., Niamir, A., Thurner, M., \& Hickler, T. (2019). Combining European Earth Observation products with Dynamic Global Vegetation Models for estimating Essential Biodiversity Variables. International Journal of Digital Earth, 1-16.

De Groot, R. S., Alkemade, R., Braat, L., Hein, L., \& Willemen, L. (2010). Challenges in integrating the concept of ecosystem services and values in landscape planning, management and decision making. Ecological complexity, 7(3), 260-272.

De Heer, M., Kapos, V., \& Ten Brink, B. J. E. (2005). Biodiversity trends in Europe: development and testing of a species trend indicator for evaluating progress towards the 2010 target. Philosophical Transactions of the Royal Society B: Biological Sciences, 360 (1454), 297-308.

Descombes, P., Vittoz, P., Guisan, A. et al. (2017) Alp Botany. 127: 53. https://doi.org/10.1007/s00035016-0173-7. 
Distler, T., Schuetz, J. G., Velasquez-Tibata, J., \& Langham, G. M. (2015). Stacked species distribution models and macroecological models provide congruent projections of avian species richness under climate change. Journal of Biogeography, 42(5), 976-988.

Dobrowski, S. Z., Thorne, J. H., Greenberg, J. A., Safford, H. D., Mynsberge, A. R., Crimmins, S. M., \& Swanson, A. K. (2011). Modelling plant ranges over 75 years of climate change in California, USA: temporal transferability and species traits. Ecological Monographs, 81(2), 241-257.

Dormann, C. F., Elith, J., Bacher, S., Buchmann, C., Carl, G., Carre, G., ...Lautenbach, S. (2013). Collinearity: A review of methods to deal with it and a simulation study evaluating their performance. Ecography, 36, 27-46. https://doi.org/10.1111/j.1600-0587.2012.07348.x

Elith, J., \& Leathwick, J. R. (2009). Species distribution models: ecological explanation and prediction across space and time. Annual review of ecology, evolution, and systematics, 40, 677-697.

Elith, J., H. Graham, C., P. Anderson, R., Dudik, M., Ferrier, S., Guisan, A., .. \& Li, J. (2006). Novel methods improve prediction of species' distributions from occurrence data. Ecography, 29(2), 129-151.

Fernandes RF, Scherrer D, Guisan A. Effects of simulated observation errors on the performance of species distribution models. Divers Distrib. 2018; 0 0:1-14.

Ferrier, S. (2002). Mapping spatial pattern in biodiversity for regional conservation planning: where to from here?. Systematic biology, 51 (2), 331-363.

Geijzendorffer, I. R., Regan, E. C., Pereira, H. M., Brotons, L., Brummitt, N., Gavish, Y., .. \& Schmeller, D. S. (2016). Bridging the gap between biodiversity data and policy reporting needs: An Essential Biodiversity Variables perspective. Journal of Applied Ecology, 53(5), 1341-1350.

GEO BON (2015) Global Biodiversity Change Indicators. Version 1.2. Group on Earth Observations Biodiversity Observation Network Secretariat. Leipzig, 20 pages.

Gogol-Prokurat, M. (2011). Predicting habitat suitability for rare plants at local spatial scales using a species distribution model. Ecological Applications, 21(1), 33-47.

Gregory et al., 2005 R.D. Gregory, A. van Strien, P. Vorisek, et al. Developing indicators for European birds

Gregory and van Strien, 2010 R.D. Gregory, A. van Strien Wild bird indicators: using composite population trends of birds as measures of environmental health Ornithol. Sci., 9 (2010), pp. 3-22

Philos. Trans. R. Soc. Lond. Ser. B Biol. Sci., 360 (2005), pp. 269-288

Gruebler, M. U., Horch, P., \& Spaar, R. (2015a). Whinchats impacted by changes in alpine grassland management: research results from Switzerland. In Living on the Edge of Extinction in Europe. Proc. 1st European Whinchat Symposium (pp. 263-273).

Gruebler, M. U., Schuler, H., Spaar, R., \& Naef-Daenzer, B. (2015b). Behavioural response to anthropogenic habitat disturbance: Indirect impact of harvesting on whinchat populations in Switzerland. Biological Conservation, 186, 52-59.

Guisan, A., Edwards, T. C. Jr and Hastie, T. (2002) Generalized linear and generalized additive models in studies of species distributions: setting the scene. Ecol. Modell. 157: 89-100. DOI: 10.1016/S03043800(02)00204-1.

Guisan, A., \& Thuiller, W. (2005). Predicting species distribution: offering more than simple habitat models. Ecology letters, 8(9), 993-1009.

Guisan, A., Edwards Jr, T. C., \& Hastie, T. (2002). Generalized linear and generalized additive models in studies of species distributions: setting the scene. Ecological modelling, 157(2-3), 89-100. 
Guisan, A., Lehmann, A., Ferrier, S., Austin, M., Overton, J. M. C., Aspinall, R., \& Hastie, T. (2006). Making better biogeographical predictions of species' distributions. Journal of Applied Ecology, 43(3), 386392 .

Guisan, A., Thuiller, W., \& Zimmermann, N. E. (2017). Habitat suitability and distribution models: with applications in R. Cambridge University Press.

Guillera-Arroita, G., Lahoz-Monfort, J. J., Elith, J., Gordon, A., Kujala, H., Lentini, P. E., .. \& \& Wintle, B. A. (2015). Is my species distribution model fit for purpose? Matching data and models to applications. Global Ecology and Biogeography, 24(3), 276-292.

Harrington, R., Anton, C., Dawson, T. P., de Bello, F., Feld, C. K., Haslett, J. R., ... \& Rounsevell, M. D. (2010). Ecosystem services and biodiversity conservation: concepts and a glossary. Biodiversity and Conservation, 19(10), 2773-2790.

Haase, P., Tonkin, J. D., Stoll, S., Burkhard, B., Frenzel, M., Geijzendorffer, I. R., .. \& Mirtl, M. (2018). The next generation of site-based long-term ecological monitoring: Linking essential biodiversity variables and ecosystem integrity. Science of the Total Environment, 613, 1376-1384.

Hardisty, A. R., Michener, W. K., Agosti, D., Garcia, E. A., Bastin, L., Belbin, L., .. \& \& De Giovanni, R. (2019). The Bari Manifesto: An interoperability framework for essential biodiversity variables. Ecological Informatics , 49 , 22-31.dimension.

Hatchwell, B. J., Chamberlain, D. E., \& Perrins, C. M. (1996). The demography of blackbirds Turdus merula in rural habitats: is farmland a sub-optimal habitat?. Journal of Applied Ecology, 1114-1124.

Henry, P. Y., Lengyel, S., Nowicki, P., Julliard, R., Clobert, J., Čelik, T., . \& \& Henle, K. (2008). Integrating ongoing biodiversity monitoring: potential benefits and methods. Biodiversity and conservation , 17 (14), $3357-3382$.

Hirzel, A. H., Le Lay, G., Helfer, V., Randin, C., \& Guisan, A. (2006). Evaluating the ability of habitat suitability models to predict species presences. Ecological modelling, 199(2), 142-152.

Hirzel, A. H., \& Le Lay, G. (2008). Habitat suitability modelling and niche theory. Journal of Applied Ecology, 45(5), 1372-1381.

Horch, P., \& Holzgang, O. (2006). Hecken für Heckenbrüter: Erkenntnisse aus den drei Inventaren 1979, 1988 und 1999 im Kanton Thurgau. Ornithol. Beob, 103, 39-56.

Horch, P., \& Spaar, R. (2010). Lo Stiaccino Saxicola rubetra, specie target per l'agricoltura estensiva. Ficedula, 45, 20-27.

Horch, P., \& Spaar, R. (2016). Landwirtschaft und Naturschutz im oberen Goms: Gemeinsamer Einsatz für das Braunkehlchen.

Hughes, L. (2000). Biological consequences of global warming: is the signal already apparent?. Trends in ecology \& evolution, 15(2), 56-61.

Huntley, B., Green, R. E., Collingham, Y. C., Hill, J. K., Willis, S. G., Bartlein, P. J., .. \& Thomas, C. J. (2004). The performance of models relating species geographical distributions to climate is independent of trophic level. Ecology letters , 7 (5), 417-426.

IUCN. (2010). IUCN Standards and Petitions Subcommittee. 2010: Guidelines for Using the IUCN Red List Categories and Criteria. Version 8.1.

Jaberg, C. \& Guisan, A. (2001) Modelling the distribution of bats in relation to landscape structure in a temperate mountain environment. Journal of Applied Ecology, 38, 1169-1181.

Jarzyna, M. A., \& Jetz, W. (2017). A near half-century of temporal change in different facets of avian diversity. Global Change Biology , 23 (8), 2999-3011. 
Jetz, W., McGeoch, M. A., Guralnick, R., Ferrier, S., Beck, J., Costello, M. J., \& Meyer, C. (2019). Essential biodiversity variables for mapping and monitoring species populations. Nature ecology 8$\}$ evolution .

Kery M., Royle J.A. (2009) Inference About Species Richness and Community Structure Using SpeciesSpecific Occupancy Models in the National Swiss Breeding Bird Survey MHB. In: Thomson D.L., Cooch E.G., Conroy M.J. (eds) Modelling Demographic Processes In Marked Populations. Environmental and Ecological Statistics, vol 3. Springer, Boston, MA.DOI: https://doi.org/10.1007/978-0-387-78151-8_28.

Kissling, W. D., Hardisty, A., Garcia, E. A., Santamaria, M., De Leo, F., Pesole, G., .. \& \& Los, W. (2015). Towards global interoperability for supporting biodiversity research on essential biodiversity variables (EBVs). Biodiversity, 16(2-3), 99-107.

Kissling, W. D., Ahumada, J. A., Bowser, A., Fernandez, M., Fernandez, N., Garcia, E. A., .. \& McRae, L. (2018). Building essential biodiversity variables (EBV s) of species distribution and abundance at a global scale. Biological reviews, 93(1), 600-625.

Knaus, P., S. Antoniazza, S. Wechsler, J. Guelat, M. Kery, N. Strebel \& T. Sattler (2018): Schweizer Brutvogelatlas 2013-2016. Verbreitung und Bestandsentwicklung der Vogel in der Schweiz und im Furstentum Liechtenstein. Schweizerische Vogelwarte, Sempach. 648S.

Knight, R. L., \& Temple, S. A. (1995). Coexistence through Management. Wildlife and recreationists: coexistence through management and research.

Korner, C. (2000). The alpine life zone under global change. Gayana Botanica, 57(1), 1-17.

Latombe, G., Pyšek, P., Jeschke, J. M., Blackburn, T. M., Bacher, S., Capinha, C., .. \& \& Hui, C. (2017). A vision for global monitoring of biological invasions. Biological Conservation, 213, 295-308.

Leathwick, J. R., Elith, J., \& Hastie, T. (2006). Comparative performance of generalized additive models and multivariate adaptive regression splines for statistical modelling of species distributions. Ecological modelling, 199(2), 188-196.

Lengyel, S., Déri, E., Varga, Z., Horváth, R., Tóthmérész, B., Henry, P. Y., . . \& Christia, C. (2008). Habitat monitoring in Europe: a description of current practices. Biodiversity and Conservation, 17 (14), 3327-3339.

Liedvogel, M. (2018). Molekulare Grundlagen und genetische Architektur des Vogelzugs. VogelwarteZeitschrift für Vogelkunde, 56(4), 324-325.

MacKenzie D.I, Nichols J.D, Royle J.A, Pollock K.H, Bailey L.A\& Hines J.EOccupancy estimation and modelling: inferring patterns and dynamics of species occurrence. 2006. Amsterdam, The Netherlands:Elsevier.

Maggini, R., Lehmann, A., Kéry, M., Schmid, H., Beniston, M., Jenni, L., \& Zbinden, N. (2011). Are Swiss birds tracking climate change?: Detecting elevational shifts using response curve shapes. Ecological Modelling, 222(1), 21-32.

Maggini, R., Lehmann, A., Zbinden, N., Zimmermann, N. E., Bolliger, J., Schröder, B., ... \& Jenni, L. (2014). Assessing species vulnerability to climate and land use change: the case of the Swiss breeding birds. Diversity and distributions, 20(6), 708-719.

Manel, S., Dias, J. M., Buckton, S. T., \& Ormerod, S. J. (1999). Alternative methods for predicting species distribution: an illustration with Himalayan river birds. Journal of Applied Ecology, 36(5), 734-747.

Mateo, R. G., Felicísimo, Á. M., Pottier, J., Guisan, A., \& Muñoz, J. (2012). Do stacked species distribution models reflect altitudinal diversity patterns?. PLoS One, 7(3), e32586.

McCaffrey, D. F., Ridgeway, G., \& Morral, A. R. (2004). Propensity score estimation with boosted regression for evaluating causal effects in observational studies. Psychological methods, 9(4), 403.

Meller, L., Cabeza, M., Pironon, S., et al. 2014. Ensemble distribution models in conservation prioritization : from consensus predictions to consensus reserve networks. Diversity and Distributions, 20, 309-321. 
Menoni, E., \& Magnani, Y. (1998). Human disturbance of grouse in France. Grouse News, 15, 4-8.

Miller, J. (2010). Species distribution modelling. Geography Compass, 4(6), 490-509.

Michener, W. K., \& Jones, M. B. (2012). Ecoinformatics: supporting ecology as a data-intensive science. Trends in ecology $\mathscr{E}$ evolution, 27 (2), 85-93.

Mokany, K., Harwood, T. D., Williams, K. J., \& Ferrier, S. (2012). Dynamic macroecology and the future for biodiversity. Global Change Biology, 18(10), 3149-3159.

Müller, M., Spaar, R., Schifferli, L., \& Jenni, L. (2005). Effects of changes in farming of subalpine meadows on a grassland bird, the whinchat (Saxicola rubetra). Journal of Ornithology, 146(1), 14-23.

Naimi, B., \& Araújo, M. B. (2016). sdm: a reproducible and extensible R platform for species distribution modelling. Ecography, 39(4), 368-375.

Palialexis, A., Georgakarakos, S., Karakassis, I., Lika, K., \& Valavanis, V. D. (2011). Prediction of marine species distribution from presence-absence acoustic data: comparing the fitting efficiency and the predictive capacity of conventional and novel distribution models. Hydrobiologia , 670 (1), 241.

Parmesan, C., \& Yohe, G. (2003). A globally coherent fingerprint of climate change impacts across natural systems. Nature, 421(6918), 37-42.

Patthey, P., Wirthner, S., Signorell, N., \& Arlettaz, R. (2008). Impact of outdoor winter sports on the abundance of a key indicator species of alpine ecosystems. Journal of applied ecology, 45(6), 1704-1711.

Patthey, P., Signorell, N., Rotelli, L., \& Arlettaz, R. (2012). Vegetation structural and compositional heterogeneity as a key feature in Alpine black grouse microhabitat selection: conservation management implications. European journal of wildlife research, 58(1), 59-70.

Pereira, H. M., Ferrier, S., Walters, M., Geller, G. N., Jongman, R. H. G., Scholes, R. J., .. \& Coops, N. C. (2013). Essential biodiversity variables. Science, 339(6117), 277-278.

Pettorelli, N., Wegmann, M., Skidmore, A., Mücher, S., Dawson, T. P., Fernandez, M., .. \& Jongman, R. H. (2016). Framing the concept of satellite remote sensing essential biodiversity variables: challenges and future directions. Remote Sensing in Ecology and Conservation, 2(3), 122-131.

Proença, V., Martin, L. J., Pereira, H. M., Fernandez, M., McRae, L., Belnap, J., . . \& Honrado, J. P. (2017). Global biodiversity monitoring: from data sources to essential biodiversity variables. Biological Conservation, 213, 256-263.

Progin, D. (2018) Modelling habitat suitability of bats in the Prealps (Master thesis), Lausanne University, Lausanne, Switzerland.

Randin, C. F., Dirnböck, T., Dullinger, S., Zimmermann, N. E., Zappa, M., \& Guisan, A. (2006). Are niche-based species distribution models transferable in space?. Journal of biogeography , 33 (10), 1689-1703.

Randin, C. F., Jaccard, H., Vittoz, P., Yoccoz, N. G., \& Guisan, A. (2009). Land use improves spatial predictions of mountain plant abundance but not presence-absence. Journal of Vegetation Science, 20(6), 996-1008.

R Core Team (2016) R: a language and environment for statistical computing. Vienna: R Foundation for Statistical Computing.

Richner, H., \& Tripet, F. (1999). Ectoparasitism and the trade-off between current and future reproduction. Oikos, 535-538.

Roth, T., Plattner, M., \& Amrhein, V. (2014). Plants, birds and butterflies: short-term responses of species communities to climate warming vary by taxon and with altitude. PloS one, 9(1), e82490. 
Rouse, J. W., Haas, R. H., Schell, J. A., \& Deering, D. W. (1974). Monitoring vegetation systems in the Great Plains with ERTS. NASA special publication, 351, 309.

Royle, J. A., Kery, M., Gautier, R., \& Schmid, H. (2007). Hierarchical spatial models of abundance and occurrence from imperfect survey data. Ecological Monographs, 77(3), 465-481.

Sattler, T., P. Knaus, H. Schmid \& B. Volet (2017): The State of Birds in Switzerland. Report 2017. Swiss Ornithological Institute, Sempach.

Scherrer, D., Christe, P., \& Guisan, A. (2019). Modelling bat distributions and diversity in a mountain landscape using focal predictors in ensemble of small models. Diversity and Distributions.

Schmid, H., Zbinden, N., \& Keller, V. (2004). Uberwachung der bestandsentwicklung haufiger brutvogel in der schweiz. Swiss Ornithological Institute Sempach Switzerland .

Schimel, D. S., Asner, G. P., \& Moorcroft, P. (2013). Observing changing ecological diversity in the Anthropocene. Frontiers in Ecology and the Environment, 11(3), 129-137.

Schmeller, D. S., Mihoub, J. B., Bowser, A., Arvanitidis, C., Costello, M. J., Fernandez, M., .. \& Saarenmaa, H. (2017). An operational definition of essential biodiversity variables. Biodiversity and conservation, 26(12), 2967-2972.

Sergio, F., \& Newton, I. A. N. (2003). Occupancy as a measure of territory quality. Journal of Animal Ecology, 72(5), 857-865.

Sheffield, J., \& Wood, E. F. (2008). Projected changes in drought occurrence under future global warming from multi-model, multi-scenario, IPCC AR4 simulations. Climate dynamics , 31 (1), 79-105.

Sigmaplan, Metron \& Meteotest (2001): Landschaft unter Druck, 2. Fortschreibung 1984-95. Bundesamt fur Raumentwicklung und Bundesamt fur Umwelt, Wald und Landschaft. Bern

Stephan, W., Wiehe, T. H., \& Lenz, M. W. (1992). The effect of strongly selected substitutions on neutral polymorphism: analytical results based on diffusion theory. Theoretical Population Biology, 41(2), 237-254.

Tittensor, D. P., Walpole, M., Hill, S. L., Boyce, D. G., Britten, G. L., Burgess, N. D., .. \& B Baumung, R. (2014). A mid-term analysis of progress toward international biodiversity targets. Science, 346(6206), 241-244.

Thuiller, W., Lavorel, S., \& Araujo, M. B. (2005). Niche properties and geographical extent as predictors of species sensitivity to climate change. Global Ecology and Biogeography, 14(4), 347-357.

Thuiller, W., Georges, D., Engler, R., Breiner, F., Georges, M. D., \& Thuiller, C. W. (2016). Package 'biomod2'.

Tulloch, A. I., \& Szabo, J. K. (2012). A behavioural ecology approach to understand volunteer surveying for citizen science datasets. Emu-Austral Ornithology, 112 (4), 313-325.

Turak, E., Brazill-Boast, J., Cooney, T., Drielsma, M., DelaCruz, J., Dunkerley, G., .. \& Koen, T. (2017a). Using the essential biodiversity variables framework to measure biodiversity change at national scale. Biological Conservation, 213, 264-271.

Turak, E., Harrison, I., Dudgeon, D., Abell, R., Bush, A., Darwall, W., .. \& J Juffe-Bignoli, D. (2017b). Essential Biodiversity Variables for measuring change in global freshwater biodiversity. Biological Conservation, 213, 272-279.

Turak, E., Regan, E., \& Costello, M. J. (2017). Measuring and reporting biodiversity change. Biological Conservation, 213, 249- 251.

Van Niel, K. P., \& Austin, M. P. (2007). Predictive vegetation modelling for conservation: Impact of error propagation from digital elevation data. Ecological Applications , 17 (1), 266-280. 
Vihervaara, P., Auvinen, A. P., Mononen, L., Torma, M., Ahlroth, P., Anttila, S., .. \& \& Koskelainen, M. (2017). How essential biodiversity variables and remote sensing can help national biodiversity monitoring. Global Ecology and Conservation, 10, 43-59.

Vincenzi, S., Zucchetta, M., Franzoi, P., Pellizzato, M., Pranovi, F., De Leo, G. A., \& Torricelli, P. (2011). Application of a Random Forest algorithm to predict spatial distribution of the potential yield of Ruditapes philippinarum in the Venice lagoon, Italy. Ecological Modelling, 222(8), 1471-1478.

Vihervaara, P., Mononen, L., Auvinen, A. P., Virkkala, R., Lu, Y., Pippuri, I., . . \& Valkama, J. (2015). How to integrate remotely sensed data and biodiversity for ecosystem assessments at landscape scale. Landscape Ecology , 30 (3), 501-516.

von dem Bussche, J., Spaar, R., Schmid, H., \& Schroder, B. (2008). Modelling the recent and potential future spatial distribution of the Ring Ouzel (Turdus torquatus) and Blackbird (T. merula) in Switzerland. Journal of Ornithology , 149 (4), 529-544.

Whitfield, D. P., Ruddock, M., \& Bullman, R. (2008). Expert opinion as a tool for quantifying bird tolerance to human disturbance. Biological Conservation , 141 (11), 2708-2717.

Wintle, B. A., McCarthy, M. A., Volinsky, C. T., \& Kavanagh, R. P. (2003). The use of Bayesian model averaging to better represent uncertainty in ecological models. Conservation biology, 17(6), 1579-1590.

Wisz, M. S., and A. Guisan. 2009. Do pseudo-absence selection strategies influence species distribution models and their predictions? An information-theoretic approach based on simulated data. BMC Ecology 9: online.

ZBINDEN, N. \& H. HALLER (2013): The Alps, their birds and what we know about them. Ornithol. Beob. 110: $249-256$.

Zeitler, A., \& Glanzer, U. (1998). Skiing and grouse in the Bavarian Alps. Grouse News, 15, 8-12.

Zeitler, A. (2000). Human disturbance, behaviour and spatial distribution of black grouse in skiing areas in the Bavarian Alps. Cahiers d'Ethologie, 20, 381-400.

Zilioli, M., Oggioni, A., Tagliolato, P., Pugnetti, A., \& Carrara, P. (2019). Feeding Essential Biodiversity Variables (EBVs): actual and potential contributions from LTER-Italy. Nature Conservation , 34, 477.

Zurell, D., Grimm, V., Rossmanith, E., Zbinden, N., Zimmermann, N. E., \& Schroder, B. (2012). Uncertainty in predictions of range dynamics: black grouse climbing the Swiss Alps. Ecography, 35(7), 590-603.

\section{Hosted file}

image2.emf available at https://authorea.com/users/361270/articles/482723-spatialpredictions-of-regional-species-distribution-essential-biodiversity-variables-sd-ebvs-abird-perspective-in-the-swiss-alps

Figure Studied area and sampling points

Table 1: Environmental variables. Description and name of each environmental variable used in the modelling process. Th

Category

Climatic

Land Cover 
Table 1: Environmental variables. Description and name of each environmental variable used in the modelling process. Th

Others

Topographic

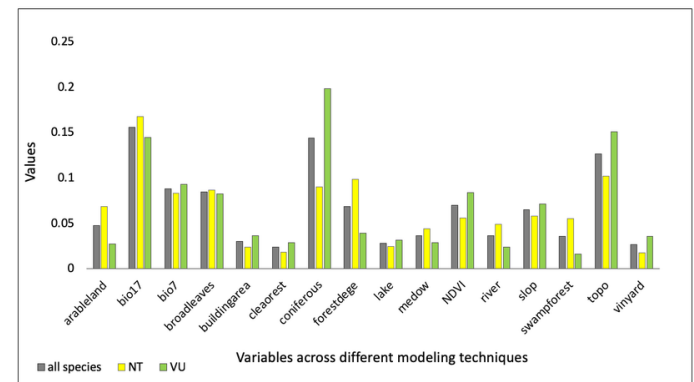

\section{Hosted file}

image4.emf available at https://authorea.com/users/361270/articles/482723-spatialpredictions-of-regional-species-distribution-essential-biodiversity-variables-sd-ebvs-abird-perspective-in-the-swiss-alps

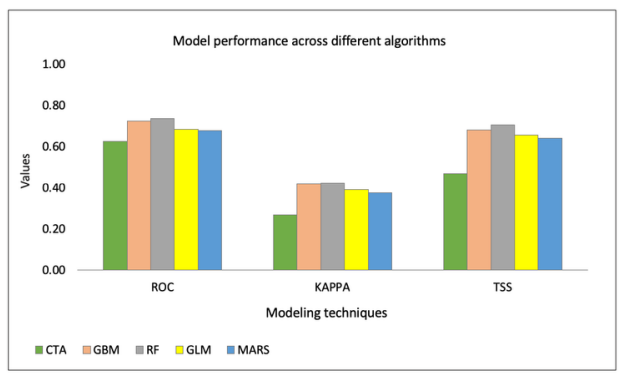




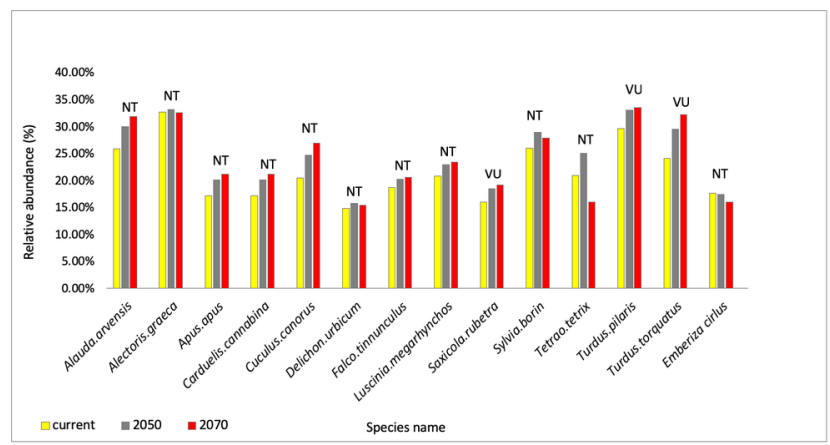

Appendix S1

\begin{tabular}{lllll}
\hline Species names & Common names & Number & RL & Habitat \\
\hline Alauda arvensis & Eurasian Skylark & 13 & NT & farmland \\
Alectoris graeca & Rock Partridge & 22 & NT & alpine habitats \\
Apus apus & Common Swift & 27 & NT & settlements \\
Carduelis cannabina & Linaria cannabina & 228 & NT & alpine habitats, farmland, gravel pits, settlements \\
Cuculus canorus & Cuculus canorus & 99 & NT & alpine habitats, forest, farmland, wetlands \\
Delichon urbicum & House Martin & 70 & NT & settlements, rocky terrain \\
Emberiza cirlus & Emberiza cirlus & 25 & NT & vineries, gravel pits, farmland \\
Falco tinnunculus & Common Kestrel & 86 & NT & farmland, settlements, alpine habitats \\
Luscinia megarhynchos & Luscinia megarhynchos & 34 & NT & bush \\
Saxicola rubetra & Whinchat & 105 & VU & meadows and pasture \\
Sylvia borin & Garden Warbler & 44 & NT & settlements, forest, hedges, wetlands \\
Tetrao tetrix & Black Grouse & 39 & NT & forest, alpine habitats \\
Turdus pilaris & Fieldfare & 132 & VU & farmland, settlements, edge of the forest, alpine habitat \\
Turdus torquatus & Ring Ouzel & 319 & VU & forest, alpine habitats \\
\hline
\end{tabular}

vinyadnew TOPO swampores SLOP riverNEW NOVI medow1 lakeNEW forestdege coniferous clearlores buildingar broadleave bionew bio17new2 arableand

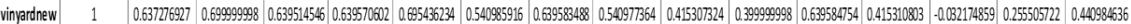

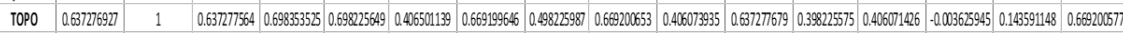

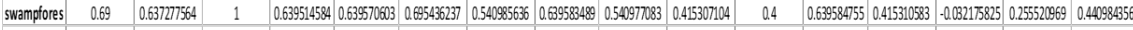

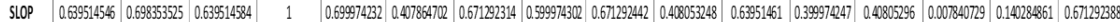

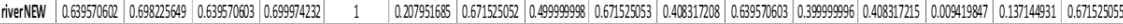

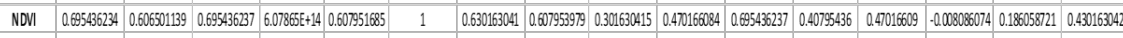

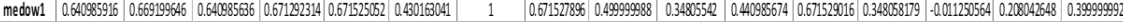

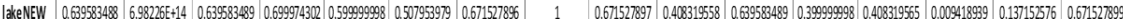

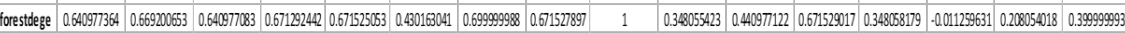

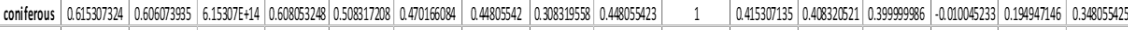

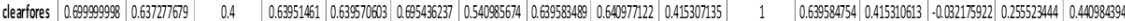

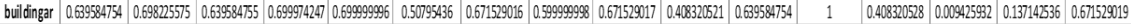

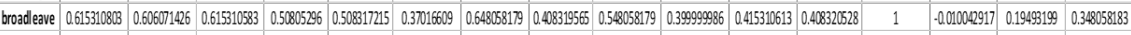

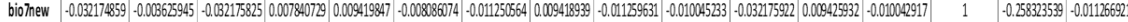

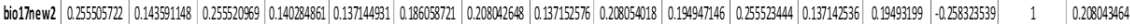

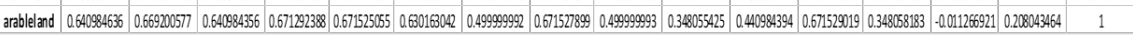




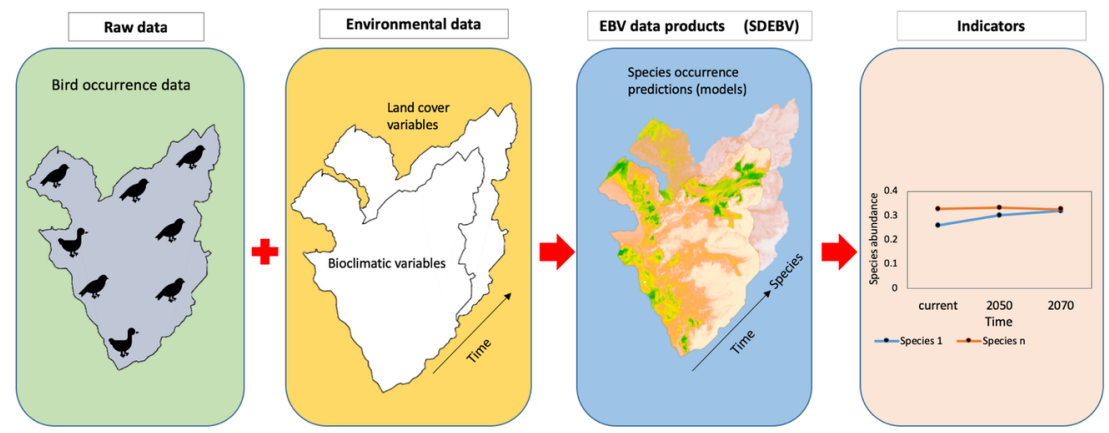

\section{Appendix S1 Details on environmental predictors}

\section{Temperature $\left[{ }^{\circ} \mathrm{C}\right]$}

The temperature data are derived from daily MeteoSwiss Grid-Data Products at $1 \mathrm{~km}$ resolution for 19812010. Maps were downscaled from $1 \mathrm{~km}$ to $25 \mathrm{~m}$ using local linear regressions with elevation $\mathrm{T} 1 \mathrm{~km}=\mathrm{a} 1 \mathrm{~km}$ $+\mathrm{b} 1 \mathrm{~km} *$ Elevation $1 \mathrm{~km}$ in a moving window of $5 \mathrm{~km}$ radius. Intercepts a1 km and slopes b1 km are then disaggregated at $25 \mathrm{~m}$ and smoothed spatially with conic density. T25m $=\mathrm{a} 25 \mathrm{~m}+\mathrm{b} 25 \mathrm{~m} *$ Elevation $25 \mathrm{~m}$ is then applied. (Broennimann, comm. pers.). The minimal temperatures were averaged daily between 1981 and 2010, and temperature from May to August were averaged. Final temperature map was aggregate to $100 \mathrm{~m}$ resolution by mean.

\section{Precipitation - preci $[\mathrm{mm} /$ period $]$}

The sums of precipitation data are derived from daily MeteoSwiss Grid-Data Products at $1 \mathrm{~km}$ resolution for 1981-2010. Maps were downscaled from $1 \mathrm{~km}$ to $25 \mathrm{~m}$ using local linear regressions with elevation $P_{1 \mathrm{~km}}$ $=a_{1 \mathrm{~km}}+b_{1 \mathrm{~km}} *$ Elevation $_{1 \mathrm{~km}}$ in a moving window of $5 \mathrm{~km}$ radius. Intercepts $\mathrm{a}_{1 \mathrm{~km}}$ and slopes $\mathrm{b}_{1 \mathrm{~km}}$ are then disaggregated at $25 \mathrm{~m}$ and smoothed spatially with conic density. $P_{25 m}=a_{25 m}+b_{25 m} *$ var(Elevation $25 m$ ) is then applied. (Broennimann, comm. pers.). The sums of precipitation were averaged daily between 1981 and 2010, and the precipitation from May to August were summed. Final precipitation map was aggregate to $100 \mathrm{~m}$ resolution by mean.

\section{Slope $\left[{ }^{\circ}\right]$}

Slope was calculated from a digital terrain model (DTM) at a $25 \mathrm{~m}$ resolution (Swisstopo OFT) by a moving window. Slope at $25 \mathrm{~m}$ was furtherly aggregated to $100 \mathrm{~m}$ resolution by mean."

\section{Building area $[0 ; 1]$}

The proportion of building area over the area calculated with a land-cover layer (Geostat 2013/2018, OFS) reclassified into two classes (Building area or not).

\section{River [0;1]}

The proportion of river area over the area calculated with a land-cover layer (Geostat 2013/2018, OFS) reclassified into two classes (river area or not).

\section{Lake $[0 ; 1]$}


The proportion of lake area over the area calculated with a land-cover layer (Geostat 2013/2018, OFS) reclassified into two classes (lake area or not).

\section{Forest $[0 ; 1]$}

The proportion of forest area over the area calculated with a land-cover layer (Geostat 2013/2018, OFS) reclassified into two classes (forest area or not).

\section{Clear Forest $[0 ; 1]$}

The proportion of clear forest area over the area calculated with a land-cover layer (Geostat 2013/2018, OFS) reclassified into two classes (forest area or not).

\section{Forest Edge $[0 ; 1]$}

The proportion of forest edge area over the area calculated with a land-cover layer (Geostat 2013/2018, OFS) reclassified into two classes (forest edge area or not).

\section{Vineyard $[0 ; 1]$}

The proportion of vineyard area over the area calculated with a land-cover layer (Geostat 2013/2018, OFS) reclassified into two classes (vineyard area or not).

\section{Arable land $[0 ; 1]$}

The proportion of Arable land area over the area calculated with a land-cover layer (Geostat 2013/2018, OFS) reclassified into two classes (Arable land area or not).

\section{"Topo []}

Topography was calculated from a digital terrain model (DTM) at a $25 \mathrm{~m}$ resolution (Swisstopo OFT) by a moving window. Topo at $25 \mathrm{~m}$ was furtherly aggregated to $100 \mathrm{~m}$ resolution by mean."

\section{Swamp Forest $[0 ; 1]$}

The proportion of swamp forest area over the area calculated with a land-cover layer (Geostat 2013/2018, OFS) reclassified into two classes (forest area or not).

\section{Normalized difference vegetation index - NDVI $[-1 ; 1]$}

Normalized difference vegetation index, calculated with an image of the area at $10 \mathrm{~m}$ resolution rescaled to $100 \mathrm{~m}$ by mean in ArcGIS 10.2 (www.esri.com). The images were taken in September and were provided by Swisstopo, OFT. A mean was calculated with a moving window of different radius to create ndvi_focal."

\section{Meadow [0;1]}

The proportion of meadow area over the area calculated with a land-cover layer (Geostat 2013/2018, OFS) reclassified into two classes (vineyard area or not). 